\title{
What's the plot?
}

Can mathematicians learn from the narrative approaches of the writers who popularize and dramatize their work? Sarah Tomlin is on the story.

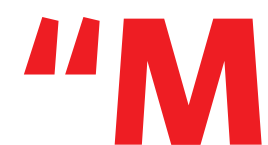

athematicians are quite shy, with very few exceptions," announced Pierre Cartier of the Institute des Hautes Études Scientifiques, south of Paris, opening his talk on mathematicians who have written autobiographies. "And most of them are in this room!" someone shouted from the floor. It was a rousing start to a highly unusual meeting.

Last month, a select group of about 30 mathematicians, playwrights, historians, philosophers, novelists and artists descended on the Greek island of Mykonos. The gathering aimed to find common ground between storytelling and mathematics, and was inspired by a profusion of books, movies and plays that, over the past decade, have dragged the subject out of a cultural wilderness.

Clearly, stories about mathematics have strong popular appeal. But what can professional mathematicians learn from the writers who are now taking an interest in their work? Can narrative approaches help the increasingly esoteric sub-fields of mathematics communicate with one another? And can such approaches help mathematicians frame the abstract problems that fill their working lives?

It was the hope of answering such questions that led the Greek novelist Apostolos Doxiadis to cook up the idea of bringing writers and mathematicians together. After graduating with a mathematics degree from New York's Columbia University at the age of 18 , Doxiadis turned to his first loves of poetry and theatre. But in his late thirties, Doxiadis revisited mathematics with his 2001 novel Uncle Petros and the Goldbach Conjecture, in which the protagonist's attempt to prove this conjecture - that every even number is the sum of two primes - becomes a universal story about courage and suffering.

Excited by the narrative possibilities offered by mathematics, Doxiadis formed a foundation to further explore the theme - called Thales \& Friends, after the first mathematician and philosopher in ancient Greece. And with financial backing from the Mathematical Sciences Research Institute in Berkeley, Califor-

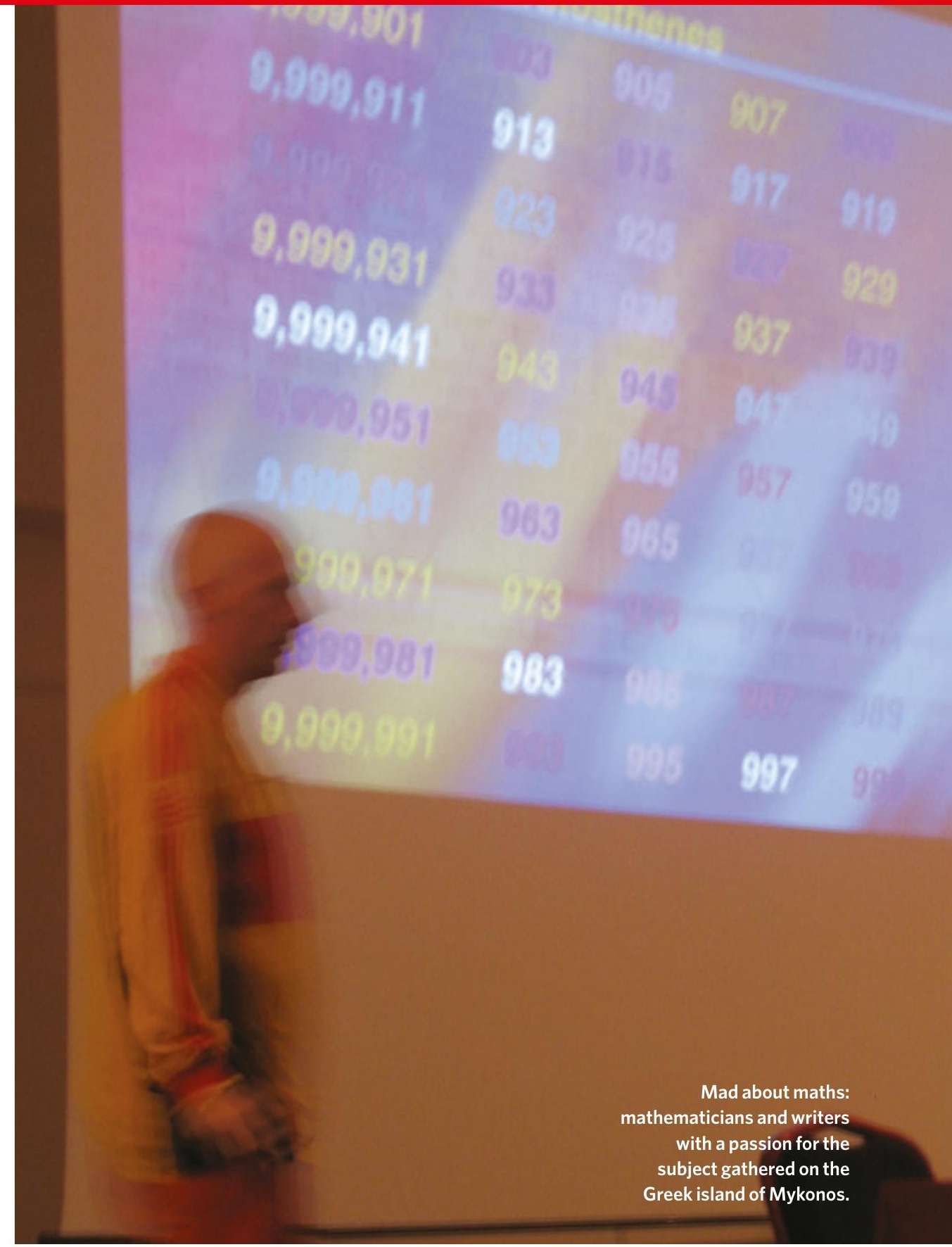

nia, he set about organizing the Mykonos meeting. At first, the plan was for a smaller informal gathering, but it soon snowballed. "I'm surprised, frankly, at the response," Doxiadis told Nature.

The venue was apt, given that ancient Greece was where the gulf between mathematics and story-telling first opened up. "Plato approved of mathematics, but despised poetry," says Rebecca Goldstein, a philosopher and novelist based in Hartford, Connecticut, who has used mathematicians as characters in several novels. Other participants blamed Euclid for introducing the impersonal, logical style that has characterized much mathematical writing ever since.

Whatever the historical reasons for the divide, it has been bridged with a vengeance in recent years. The spark came in 1995, with the solution of Fermat's last theorem by the British proof made prime-time news, and was followed by a best-selling book, Fermat's Enigma by Simon Singh. Suddenly mathematics was fashionable. Next came a host of popular is books on subjects such as zero, pi and irrational numbers, the Hollywood movie A Beautiful Mind, and plays such as David Auburn's Proof and John Barrow's Infinities. Today, there is even a US television series called Numb3rs, in which a detective relies on the skills of his mathematical-genius brother to solve crimes.

But if it is possible to tell stories about mathematics to a general audience, why do specialists in different branches of the discipline have so much difficulty communicating with one another? "Most mathematics papers are incomprehensible to most mathematicians," complains Tim Gowers of the University of Cambridge, UK, winner of a 1998 Fields mathematician Andrew Wiles. His 100-page 


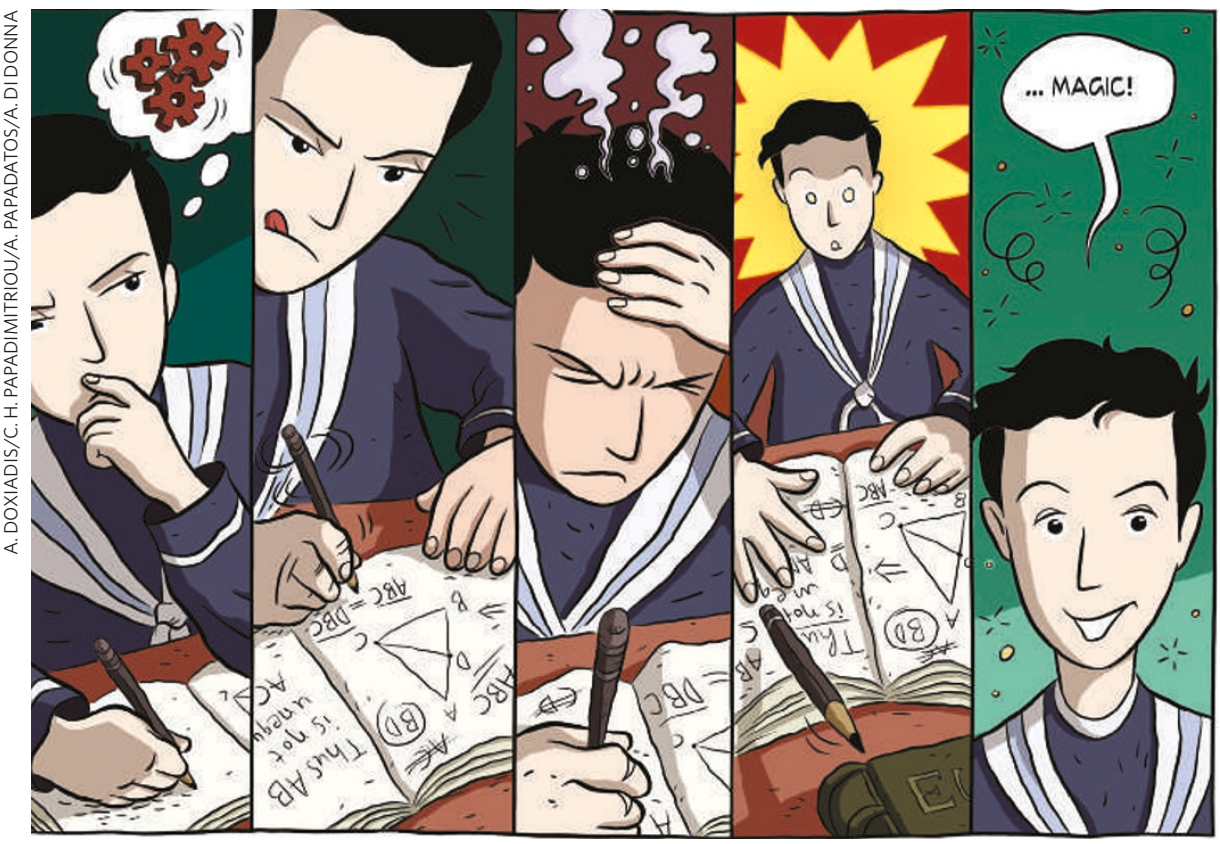

Brought to life: Alecos Papadatos' graphic novel has been inspired by the lives of logicians.

Medal — the nearest thing the subject has to a Nobel prize. "Publication has become just a formal stamp of approval - it is not a means of communication anymore," he adds.

Gowers is currently editing the Princeton Companion to Mathematics, which is scheduled to appear in 2006 and is intended to provide budding mathematicians with an accessible overview of the field. "Say you decided you wanted to do research in mathematics but you didn't know what area would appeal to you," says Gowers. "There is nothing available right now."

\section{Tales of tables}

Narrative approaches can help make arcane branches of mathematics more accessible to specialists, as well as to the lay public, Gowers argues. Persi Diaconis, a statistician at Stanford University in California, agrees. "I can only work on problems if there is a story that is real for me," he says. As one of the few applied mathematicians at the meeting, Diaconis perhaps has an easier time than most in applying narratives to his work. In Mykonos, he picked three of his papers, and told a story about each.

The first was a 1987 paper entitled 'Projection pursuit for discrete data, which deals with a mathematical technique for finding patterns in data in a systematic way. To make this technique come alive, Diaconis chose a real-life problem - the dating of Plato's most important texts. Scholars had previously classified the last five syllables of Plato's sentences as either 'short' or 'long', in the expectation that his writing style had changed over time, and that this would show up in these data. But they struggled to find anything meaningful. By looking at pairs of syllables using his technique, Diaconis was able to find patterns in the texts that had previously been hidden, and could subsequently work out an order for Plato's works.
Diaconis learned to love the abstraction of pure mathematics from his tutor Barry Mazur of Harvard University. But Mazur admits that he used to be mystified when Diaconis would ask: "I'm lost. What's the story?" Today, Mazur says he has woken up to the power of narrative, and in Mykonos gave an example of a 20-year unsolved puzzle in number theory which he described as a cliff-hanger. "I don't think I personally understood the problem until I expressed it in narrative terms," Mazur told the meeting. He argues that similar narrative devices may be especially helpful to young mathematicians, who seem particularly poor at explaining their work to others.

Mazur explained that he used narrative to help him develop a general organizing structure around the problem, which involves a conflict between theory and the large amount of data gathered on elliptic curves. Mazur did not find a solution by using the narrative device of a cliff-hanger, but it helped him to frame the question - and that, he argues, may be as important.

Mazur's explorations of narrative may sound trivial. And some of the writers who attended the Mykonos meeting admitted that they were left cold by this particular story. But Doxiadis explains that mathematicians, unlike experimental scientists, aren't used to dealing with conflicts between data and theory in this way. They like to understand a problem at its most basic level, from the inside. So for a mathematician, Mazur's depic-

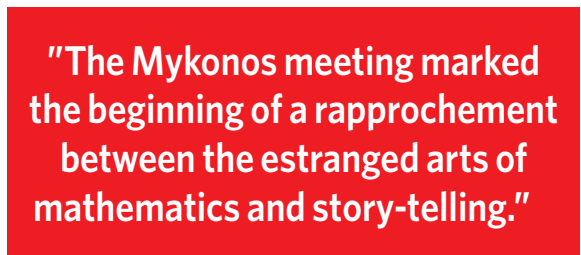

tion of his number-theory problem in dramatic terms might be a genuine eye-opener. "The thing that inspired me was the idea that this could affect mathematics itself," says philosopher David Corfield of the Max Planck Institute for Biological Cybernetics in Tübingen, Germany.

\section{Maths fever}

In general, the non-mathematicians in Mykonos were passionate about the mathematical ideas that they have encountered. Alecos Papadatos is a cartoonist who is working on a graphic novel with Doxiadis and others about the history of logicians, most of whom died tragically. He claims he never liked mathematics, but now sees that the discipline is full of exciting stories. Barbara Oliver, who is artistic director of a theatre in Berkeley, California, echoes his view. She enjoyed directing the play Partition by Ira Hauptman — which is loosely based on the lives of two very different mathematicians, G. H. Hardy and Srinivasa Ramanujan - despite her lack of specialist knowledge. "I'm untutored, unskilled in mathematics," she says.

Whether mathematicians are similarly eager to embrace the joys of narrative remains unclear - particularly if telling a good story involves compromising standards of mathematical accuracy. Some of the most heated discussions in Mykonos were about the mistakes in a recent popular book on infinity, and whether they really matter. Diaconis, despite being an enthusiastic story-teller, still sees a sharp tension between narrative and mathematics. "To communicate we have to lie. If we don't we're deadly boring," he says. Diaconis waited until his 60th birthday to start writing a book on mathematics and magic, and he understands why others are cautious. "There's no reward for expository stuff, and a bias against it," he says.

Still, the Mykonos meeting at least marked the beginning of a rapprochement between the estranged arts of mathematics and story-telling. Another meeting is planned for next year and there is much work to be done, if the tales of the thorniest mathematical problems are ever to be told. Take the Hodge conjecture: according to the website of the Clay Mathematics Institute in Cambridge, Massachusetts, which is offering a US $\$ 1$ million prize to anyone who can prove it, this asserts that "for particularly nice types of spaces called projective algebraic varieties, the pieces called Hodge cycles are actually (rational linear) combinations called algebraic cycles".

If that makes no sense to you, don't worry most mathematicians regard the Hodge conjecture as 'unexplainable'. Let's hope, at least for the sake of the journalists who must try to communicate the essence of the conjecture to the general public if it is ever proved, that mathematicians will by then have honed their narrative skills.

Sarah Tomlin is a senior news feature editor for Nature. 